\title{
Use of nPSi- $\beta$ CD Composite Microparticles for the Controlled Release of Caffeic Acid and Pinocembrin, Two Main Polyphenolic Compounds Found in a Chilean Propolis
}

\author{
Dina Guzmán-Oyarzo ${ }^{1}$, Tanya Plaza ${ }^{2}$, Gonzalo Recio-Sánchez ${ }^{2,3}$, Dulcineia S. P. Abdalla ${ }^{4}$, \\ Luis A. Salazar ${ }^{1, *}$ and Jacobo Hernández-Montelongo ${ }^{2,3, *(D)}$
}

1 Center of Molecular Biology and Pharmacogenetics, Scientific and Technological Bioresource Nucleus (BIOREN), Universidad de La Frontera, Avenida Francisco Salazar 01145, Temuco 4811230, Chile; dina.guzman.o@gmail.com

2 Bioproducts and Advanced Materials Research Center (BioMA), Faculty of Engineering, Universidad Católica de Temuco, Avenida Rudecindo Ortega 02950, Temuco 4813302, Chile; tplaza.neira@gmail.com (T.P.); grecio@uct.cl (G.R.-S.)

3 Department of Physical and Mathematical Sciences, Faculty of Engineering, Universidad Católica de Temuco, Temuco 4813302, Chile

4 Department of Clinical and Toxicological Analyses, Faculty of Pharmaceutical Sciences, Universidade de São Paulo, Avenida Professor Lineu Prestes 580, CEP 05508-000 São Paulo, SP, Brazil; dspabdalla@gmail.com

* Correspondence: luis.salazar@ufrontera.cl (L.A.S.); jacobo.hernandez@uct.cl (J.H.-M.); Tel.: +56-452-596724 (L.A.S.); +56-452-553947 (J.H.-M.)

Received: 13 May 2019; Accepted: 17 June 2019; Published: 19 June 2019

check for updates

\begin{abstract}
Propolis is widely recognized for its various therapeutic properties. These are attributed to its rich composition in polyphenols, which exhibit multiple biological properties (e.g., antioxidant, anti-inflammatory, anti-angiogenic). Despite its multiple benefits, oral administration of polyphenols results in low bioavailability at the action site. An alternative to face this problem is the use of biomaterials at nano-micro scale due to its high versatility as carriers and delivery systems of various drugs and biomolecules. The aim of this work is to determine if $n P S i-\beta C D$ microparticles are a suitable material for the load and controlled release of caffeic acid (CA) and pinocembrin (Pin), two of the main components of a Chilean propolis with anti-atherogenic and anti-angiogenic activity. Polyphenols and nPSi- $\beta C D$ microparticles cytocompatibility studies were carried out with human umbilical vein endothelial cells (HUVECs). Results from physicochemical characterization demonstrated $n P S i-\beta C D$ microparticles successfully retained and controlled release CA and Pin. Furthermore, nPSi- $\beta C D$ microparticles presented cytocompatibility with HUVECs culture at concentrations of $0.25 \mathrm{mg} / \mathrm{mL}$. These results suggest that $\mathrm{nPSi}-\beta C D$ microparticles could safely be used as an alternate oral delivery system to improve controlled release and bioavailability of CA or Pin-and eventually other polyphenols—-thus enhancing its therapeutic effect for the treatment of different diseases.
\end{abstract}

Keywords: controlled release; nanoporous silicon; $\beta C D$ polymer; caffeic acid; pinocembrin; polyphenols; HUVECs

\section{Introduction}

Since ancient times, the use of natural compounds has been of great importance for medicine mainly in the prevention and treatment of different pathologies [1,2]. That is why they represent the main source of used compounds in the discovery and/or development of new drugs [3]. An example of natural compounds with bioactive potential is propolis, which is a resinous compound produced 
by bees from plants exudates. Studies both in vitro and in vivo have identified a wide variety of biological activities for propolis: antibacterial [4], antifungal [5], antioxidant [6], anti-inflammatory [7], anti-carcinogenic [8] and anti-angiogenic [9]. These activities are attributed to its polyphenols rich composition, molecules that present different biological properties: relaxing [10], antioxidant [11], antithrombotic [12], antiangiogenic [13], anti-inflammatory [14], anti-carcinogenic [15], among others. Biochemically, polyphenols are secondary metabolites exclusively synthesized by plants and their entire structure is based in one or more hydroxyl groups attached to an aromatic ring (benzene) [16]. Since the role of polyphenols in plants is related to growth, development and defense, they are found in leaves, fruits and seeds, as well as in a wide range of food of plant origin (vegetables, tea, cocoa, wine, etc.) [17]. Concerning to the presence and abundance of polyphenols in propolis, they are very variable due to their close dependence with the botanical origin of plants, climate, geographical location, year and time of collection $[3,18,19]$. Examples of this important dependence are the studies of three Brazilians, one Polish and one Chilean propolis. For the Brazilians propolis, Daleprane et al. [9] reported that artepellin $\mathrm{C}$, pinocembrin and kampferol were the main components of green propolis; 3-hydroxy-8,9-dimethoxypterocarpane, medicarpine and daidezein were the main components of red propolis; and pinocembrin, phenyl ester of caffeic acid, quercetin and galangin were the main components of brown propolis. For the Polish propolis, Szliszka et al. [20] detected that was mainly composed by the flavonoids pinobanksin, chrysin and methoxyflavanone; and the phenolics acids coumarin, ferulic and caffeic. Finally, for the Chilean propolis with anti-atherogenic and anti-angiogenic activity [21], the main polyphenols detected in the ethanolic extract were caffeic acid (a phenolic acid) and pinocembrin (a flavonone) [22].

Daily intake of polyphenols has multiple health benefits [23] because they reduce the risk of developing non-communicable diseases such as diabetes [11], cancer [24] and cardiovascular diseases [25]. In vivo studies reported that supplementation of the diet with persimmon extract rich in polyphenols maintains plasma lipid levels in hypercholesterolemic mice [26]; whereas the use of a mixture of resveratrol, CA and catechin significantly reduces the atheroma plaque in ApoE knockout mice [27]. Although the consumption of polyphenols contributes to the prevention of diseases, its oral administration without compound protection translates into a low efficiency at the action site. This is due to several factors such as concentration, binding site, chemical structure, stability in the gastrointestinal environment and aqueous solubility, which, in general, have a negative impact on absorption levels, metabolization degree, distribution throughout the body, life span and compound excretion $[2,28]$. Finally, the pharmacokinetics of polyphenols is also influenced by age, health status, intestinal microbiota and diet of patients, as well as by their oral antibiotic treatments $[29,30]$. All of the above is translated into different reports of low bioavailability of polyphenols, for example, $0.56-4.54$ $\mathrm{nmol} / \mathrm{L}$ for anthocyanins [31], $0.46-1.28 \mu \mathrm{mol} / \mathrm{L}$ for flavonones [32], and 37-60 nmol/L for phenolic acids [33].

Due to the low bioavailability of polyphenols after oral intake, several strategies have been developed to improve the bioavailability and bioactivity of these compounds. One of them is the use of microparticles based on biomaterials whose main function is to protect and transport the entire biomolecule [34]. Concerning this, nanoporous silicon (nPSi), is an excellent biomaterial that has been successfully used for the controlled release of different drugs and biomolecules, due to its large surface area, porous structure, biocompatibility, biodegradability, bioresorbability and resistance to low $\mathrm{pH}$ [35-37]. Moreover, because of the versatility of its surface chemistry, different functionalization strategies routes have been explored in order to enhance the load and controlled release of drugs [38]. A refined technique is to embed polymers into their nanopores to form composites [39]. In this regard, $\beta$-cyclodextrin $(\beta C D)$, which is a biocompatible and aqueous soluble molecule, has been successfully used in drug delivery applications. The wide application of $\beta C D$ in this field is related to the possibility to form the "host-guest" complexation ( $\beta \mathrm{CD} / \mathrm{drug}$ ) [40]; drugs are encapsulated into its lipophilic cavity structure, whereas its outer hydrophilic surface can be crosslinked with other molecules (i.e., citric acid), yielding a 3D-polymer network suitable for drug delivery applications. Therefore by combining 
a flexible and soft $\beta C D$ polymer within the highly porous inorganic matrix of nPSi as substrate, both stability and control of drugs release can be improved, increasing their therapeutic potential by reducing their degradation before they reach the target tissues [40]. Based on this, we hypothesize that $n P S i-\beta C D$ composite is a safe alternative system for oral administration of CA and Pin since it has no toxic effects on human cells. The aim of this work is to determine if nPSi- $\beta$ CD microparticles are a suitable and safe material for the load and controlled release of caffeic acid (CA) and pinocembrin (Pin), two of the main components of a Chilean propolis with anti-atherogenic and anti-angiogenic activity. This study includes the synthesis and physicochemical characterizations of nPSi- $\beta C D$ microparticles loaded or not with CA or Pin, their respective release profiles and the corresponding cytocompatibility tests for each polyphenol and composite.

\section{Materials and Methods}

\subsection{Materials}

Caffeic acid (CA, $M_{\mathrm{W}} \approx 180.16 \mathrm{~g} / \mathrm{mol}$ ), pinocembrin (Pin, $M_{\mathrm{W}} \approx 256.25 \mathrm{~g} / \mathrm{mol}$ ), chitosan (Chi, $75-85 \%$ deacetylated, low $\left.M_{\mathrm{W}} \approx 5 \times 10^{4} \mathrm{~g} / \mathrm{mol}\right), \beta$-cyclodextrin $\left(\beta C D, M_{\mathrm{W}} \approx 1134.98 \mathrm{~g} / \mathrm{mol}\right)$, citric acid $\left(M_{\mathrm{W}} \approx 210.14 \mathrm{~g} / \mathrm{mol}\right), \mathrm{g} \mathrm{NaH} \mathrm{PO}_{2} \cdot \mathrm{H}_{2} \mathrm{O}\left(M_{\mathrm{W}} \approx 105.99 \mathrm{~g} / \mathrm{mol}\right)$ and phosphate buffer solution (PBS) 0.01 $\mathrm{M}\left(0.138 \mathrm{M} \mathrm{NaCl}, 0.0027 \mathrm{M} \mathrm{KCl}, \mathrm{pH}=7.4\right.$ at $\left.25^{\circ} \mathrm{C}\right)$ were purchased from MiliporeSigma, St. Louis, MO, USA. Acetone $\left(\mathrm{C}_{3} \mathrm{H}_{6} \mathrm{O}\right)$, dimethyl sulfoxide (DMSO, $\left.\mathrm{C}_{2} \mathrm{H}_{6} \mathrm{OS}\right)$, isopropanol $\left(\mathrm{C}_{3} \mathrm{H}_{7} \mathrm{OH}\right)$, ethanol (EtOH, $\left.\mathrm{C}_{2} \mathrm{H}_{5} \mathrm{OH}\right)$, glacial acetic acid $\left(\mathrm{CH}_{3} \mathrm{COOH}\right)$, hydrogen peroxide $\left(\mathrm{H}_{2} \mathrm{O}_{2}\right)$, sodium hydroxide $(\mathrm{NaOH})$, hydrochloric acid $(\mathrm{HCl})$ and hydrofluoric acid $(\mathrm{HF})$ were acquired from Merck, Darmstadt, Germany. All chemicals were used without further purification, and solutions were prepared using Milli-Q water with resistivity of $18.2 \mathrm{M} \cdot \Omega \cdot \mathrm{cm}\left(\mathrm{pH} \sim 7.6\right.$, otherwise mentioned). Silicon (Si) wafers ( $\mathrm{p}^{+}$type, boron-doped, orientation $<100>$ resistivity of $0.001-0.005 \Omega \cdot \mathrm{cm}$ ) were purchased from University Wafer, South Boston, MA, USA. Fetal bovine serum (FBS), L-Glutamine, penicillin-streptomycin solution and D-PBS were purchased from Corning, Manassas, VA, USA. CellTiter-FluorTM assay and the CellTiter 96 ${ }^{\circledR}$ AQueous One Solution cell proliferation assay (MTS) were acquired from Promega, Madison, WI, USA.

\subsection{Sample Preparation}

Si wafers were cleaned by ultrasonication in acetone, isopropanol and distilled water, for a period of $15 \mathrm{~min}$ in each solvent. Acetone removed greasy and oily substances; isopropanol was necessary to rinse acetone off, and distilled water removed any isopropanol residues. Then, nPSi layers were fabricated by electrochemical etching from the cleaned Si wafers in HF (48\%):EtOH (1:2) solution under controlled formation conditions: etching time of $30 \mathrm{~min}$ and current density of $80 \mathrm{~mA} \cdot \mathrm{cm}^{-2}$. Afterward, an electropolishing pulse was applied to get free-standing nPSi layers. For that, the applied current density was enhanced to $150 \mathrm{~mA} / \mathrm{cm}^{2}$ during $2 \mathrm{~s}$. nPSi free-standing layers were scraped with a diamond tip to obtain microparticles. They were milled, collected in EtOH and subjected to 10 min ultrasound agitation for homogenization. Finally, the obtained nPSi particles were chemically oxidized by $\mathrm{H}_{2} \mathrm{O}_{2}(30 \%, v / v)$ for $12 \mathrm{~h}$ in orbital agitation and rinsed with $\mathrm{EtOH}$ (Figure $\left.1 \mathrm{~A}\right)$.

Oxidized nPSi microparticles were the substrate to synthetize the composite according to the protocol of Hernandez-Montelongo et al. [41] (Figure 1B). nPSi microparticles were immersed in a Chi solution for $15 \mathrm{~min}$ and after rinsed with $\mathrm{EtOH}$ (nPSi-CHI). The Chi solution (1\% w/v) was previously prepared with Chi powder in $100 \mathrm{mM}$ glacial acetic acid, then, the $\mathrm{pH}$ value was adjusted at 4 with a $0.1 \mathrm{M} \mathrm{HCl}$ and/or $\mathrm{NaOH}$ solution. For the composites (nPSi- $\beta C D$ ) synthesis, a monomer solution was prepared with $10 \mathrm{~g} \beta C D, 3 \mathrm{~g} \mathrm{NaH} \mathrm{PO}_{2} \cdot \mathrm{H}_{2} \mathrm{O}$ as catalyst, and $10 \mathrm{~g}$ citric acid in $100 \mathrm{~mL}$ of distilled water. Then, nPSi-Chi was immersed in this solution for $15 \mathrm{~min}$ while stirring. Samples were dried, first at room temperature, and later at $90^{\circ} \mathrm{C}$ for $1 \mathrm{~h}$ in each case. The $\beta \mathrm{CD}$-citric acid in situ polymerization in nPSi-CHI was carried out at $140{ }^{\circ} \mathrm{C}$ for $25 \mathrm{~min}$. Afterward, samples were rinsed with EtOH, dried at $90{ }^{\circ} \mathrm{C}$ for $1 \mathrm{~h}$ and milled for homogenization. 
A

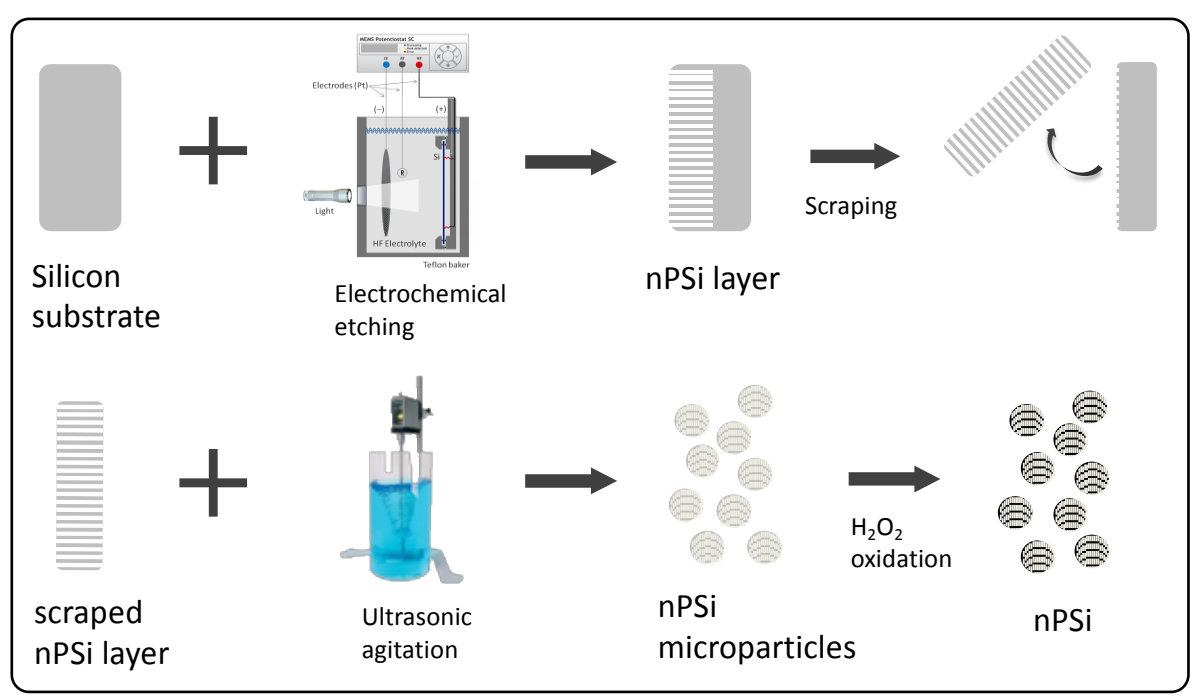

B

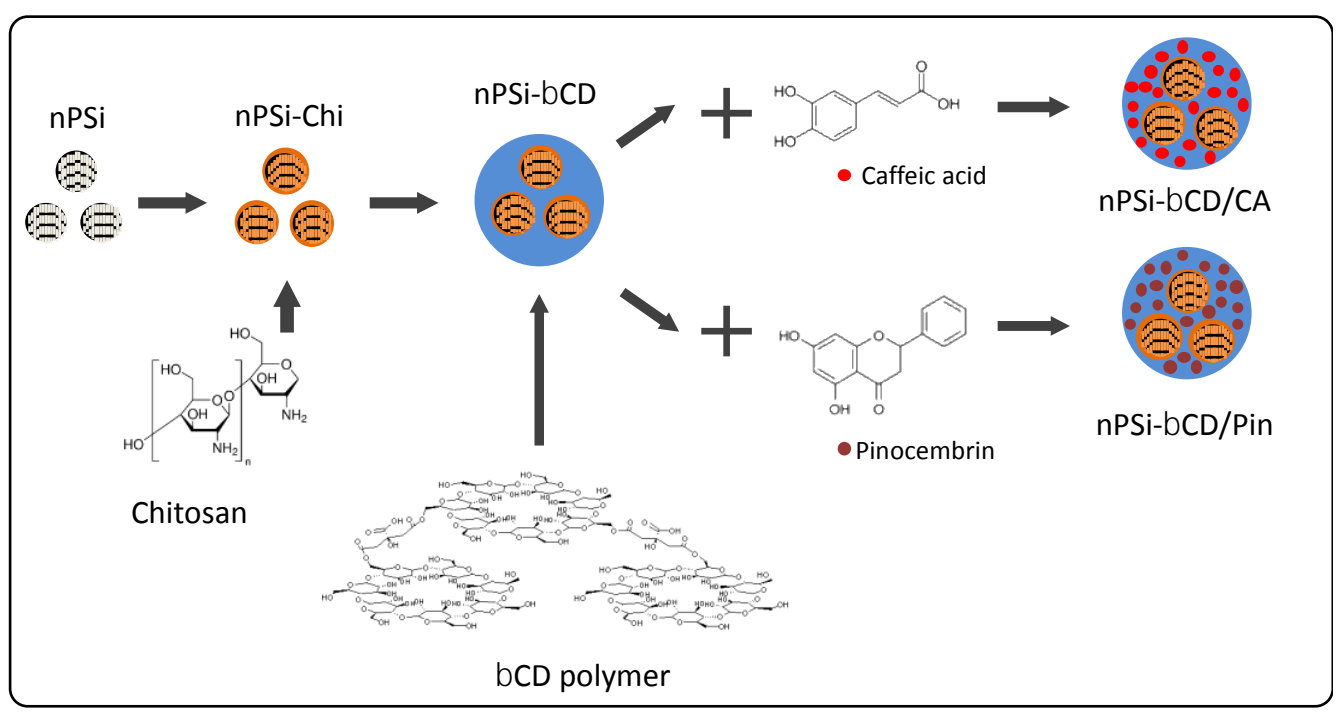

Figure 1. Experimental scheme for the synthesis of: (A) nPSi microparticles, and (B) nPSi- $\beta C D$ composite microparticles. nPSi: nanoporous silicon, $\beta C D$ : $\beta$-ciclodextrin polymer.

\subsection{Physicochemical Characterization}

The zeta potential of samples was measured by a ZetaSizer Nano-ZS (Malvern Ltd., Royston, UK) in distilled water. Attenuated total reflectance Fourier-transform infrared spectroscopy (ATR-FTIR) was used for chemical analyses of the microparticles. An FTIR spectrometer (CARY 630 FTIR Agilent Technologies, Santa Clara, CA, USA) was used in a range between 4000 and $600 \mathrm{~cm}^{-1}$ with a resolution of $1 \mathrm{~cm}^{-1}(\mathrm{NS}=4)$. The obtained spectra were mathematically processed by data smoothing and spectral normalized. The morphology of the samples was investigated by a variable pressure scanning electron microscope (VP-SEM, SU-3500 Hitachi, Tokyo, Japan) using an acceleration voltage of 5 $\mathrm{kV}$. The size distribution of samples was presented as histograms; data was obtained from the SEM images that were processed using freely available ImageJ software, version 1.52k, National Institutes of Health, Bethesda, Maryland, USA. The atomic percentage was obtained by energy-dispersive $X$-ray analysis (EDX) with an INCA X-sight from Oxford Instruments within the VP-SEM equipment. Thermogravimetric analyses (TGA) were conducted in a $\mathrm{N}_{2}$ atmosphere at a heating rate of $10^{\circ} \mathrm{C} / \mathrm{min}$ 
(DTG-60H Shimadzu, Tokyo, Japan). Porosity of nPSi samples was obtained by gravimetric analysis according to the following equation:

$$
\% P=\left(m_{1}-m_{2} / m_{1}-m_{3}\right) \times 100
$$

where $m_{1}$ is the mass of $\mathrm{Si}$ wafer before electrochemical etching, $m_{2}$ is the mass of sample just after anodization and $m_{3}$ is the mass of sample after a rapid dissolution of the whole porous layer in a $3 \%$ $\mathrm{KOH}$ solution.

\subsection{Polyphenols Loading}

Polyphenols, CA and Pin, were reconstituted with $100 \%$ DMSO $(200 \mu \mathrm{M})$ and stored at $-20{ }^{\circ} \mathrm{C}$ until required. Five $\mathrm{mg}$ of samples were loaded with $\mathrm{CA}$ and Pin using $1 \mathrm{~mL}$ of concentrated aqueous solution of each polyphenol $(2 \mathrm{mM})$ and placed in a horizontal shaker incubator (NB-2005LN Biotek, Winooski, VT, USA) for $12 \mathrm{~h}$ at $50 \mathrm{RPM}$ and room temperature. After polyphenol loading, samples were rinsed to remove the unentrapped molecules, they were dried at room temperature and milled for homogenization. To determine the maximum polyphenol loading, samples were hydrolyzed in $0.1 \mathrm{M}$ $\mathrm{NaOH}$ solutions then they were analyzed by UV-visible spectrometry (UVmini-1240 spectrometer Shimadzu, Tokyo, Japan). CA and Pin were detected at 310 and $322 \mathrm{~nm}$, respectively. Polyphenol entrapment efficiency (\%PEE) and polyphenol loading efficiency (\%PLE) and were calculated from Equations (2) and (3), respectively [42]:

$$
\begin{aligned}
& \% P E E=\left(m_{p_{-} m} / m_{p_{-}} i\right) \times 100 \\
& \% P L E=\left(m_{p_{-} m} / m_{m}\right) \times 100
\end{aligned}
$$

where $m_{p_{-} m}$ is the mass of polyphenol in microparticles, $m_{p_{-} i}$ is the mass of polyphenol fed initially and $m_{m}$ is the mass of microparticles.

\subsection{Polyphenols Release Profiles}

Polyphenols release data were collected at different times using $5 \mathrm{mg}$ of charged samples in $3 \mathrm{~mL}$ of PBS solution $\left(37^{\circ} \mathrm{C}\right)$ as release medium in agitation at $100 \mathrm{RPM}$. All experiments were conducted in triplicate and nPSi samples were used as controls in these kinetic experiments.

In order to determine the mechanism of drug release, three models were fitted to the release profiles: First order, Higuchi and Korsmeyer-Peppas models. The first order equation is [43]:

$$
\ln M_{t}-\ln M_{0}=k_{1} t
$$

where $M_{t}$ is the absolute cumulative amount of drug released at time point $t, M_{0}$ is the initial amount of drug in the solution, and $k_{1}$ is the first order release kinetic constant. The Higuchi equation is [44]:

$$
M_{t}=k_{H} t^{1 / 2}
$$

where $M_{t}$ is the absolute cumulative amount of drug released at time point $t$, and $k_{H}$ is Higuchi release kinetic constant. The Korsmeyer-Peppas semiempirical model is given by [45]:

$$
M_{t} / M_{\infty}=k_{K P} t^{n}
$$

where $M_{t} / M_{\infty}$ is the fractional drug release, $t$ is the release time, $k_{K P}$ is the Korsmeyer-Peppas release kinetic constant and $n$ is an exponent which characterizes the mechanism of release. The fitting of models was conducted with SigmaPlot v14.0, Systat Software, Inc., San Jose, USA. 


\subsection{Cytotoxicity Assays}

\subsubsection{Cell Culture}

For cell culture, human umbilical vein endothelial cells (HUVECs) were obtained from the Cell Applications Inc (San Diego, CA, USA), and maintained in Endothelial Cell Growth Medium (Cell Applications, San Diego, CA, USA) supplement with 10\% FBS, 1\% L-Glutamine and 1\% penicillin-streptomycin solution. The cell culture was routinely grown under specific conditions in a humidified atmosphere incubator of $95 \%$ air and $5 \% \mathrm{CO}_{2}$ at $37{ }^{\circ} \mathrm{C}$. Cells were used at no more than seven passages.

\subsubsection{Polyphenols Cytotoxicity}

For the in vitro viability assays, CellTiter $96^{\circledR}$ Aqueous One Solution Cell Proliferation Assay (MTS) Promega (Madison, WI, USA) was used to determine the toxic effect of CA and Pin on HUVECs viability. The MTS assay is based on the conversion of a tetrazolium salt into a colored aqueous soluble formazan product by mitochondrial activity of viable cells at $37^{\circ} \mathrm{C}$. The amount of formazan produced by dehydrogenase enzymes is directly proportional to the number of living cells in culture. The viability assays were performed according to the manufacturer's protocols. HUVECs were briefly placed into 96-well plates $\left(2.5 \times 10^{3}\right.$ cells/per well $)$ in $100 \mu \mathrm{L}$ and incubated at $37^{\circ} \mathrm{C}$. Then, cells were exposed to increase concentrations up to $2000 \mu \mathrm{M}$ of polyphenols. The compound was prepared in dimethylsulfoxide (DMSO). After $24 \mathrm{~h}$ of incubation, the medium was removed and $20 \mu \mathrm{L}$ MTS reagent was added to the wells, followed by a 4 -h incubation at $37^{\circ} \mathrm{C}$. The absorbance was determined by a microplate reader (NanoQuant, Infinite ${ }^{\circledR}$ M200PRO-Tecan, Redwood, CA, USA) at $490 \mathrm{~nm}$. Results were expressed as the percentage of viability relative to the control. The cell viability was calculated as follows: cell viability $(\%)=(\mathrm{OD}$ of treatment group/OD of control group $) \times 100$. Dose-dependent viability curves were determined using the cell viability trends.

\subsection{3. nPSi- $\beta C D$ Composite Cytotoxicity}

To determine the effect of the composite (nPSi- $\beta C D$ ) on HUVEC cell viability, a CellTiter-Fluor ${ }^{\mathrm{TM}}$ Cell Viability assay (Promega, Madison, WI, USA) was used. This assay measures a conserved and constitutive protease activity within live cells using a fluorogenic peptide substrate (glycyl-phenylalanyl-aminofluorocoumarin; GF-AFC). The substrate enters intact cells where it is cleaved by the live-cell protease activity to generate a fluorescent signal proportional to the number of living cells. $1 \times 10^{5}$ cells were exposed to different concentrations of composite and were photographed using a confocal laser microscope (CLSM, FV1000 Olympus, Tokyo, Japan) with excitation and emission wavelengths of $390 \mathrm{~nm}$ and $505 \mathrm{~nm}$, respectively. The assay was performed according to the manufacturer's protocols. The fluorescence intensity analysis was performed with Olympus Fluoview (FV10 v2.0c) software (Olympus Corporation, Tokyo, Japan). Data was analyzed statistically by analysis of variance (ANOVA) using Kruskal-Wallis test, and post-hoc test were also conducted using Dunn's multiple comparisons. The level of significance was $p<0.05$ and the results were expressed as the arithmetic mean of three biological replicates with its corresponding standard deviation. The statistical analysis was performed using the GraphPad Prism v7.0c (GraphPad Software, San Diego, CA, USA).

\section{Results and Discussion}

As the synthesis of composite microparticles was obtained by electrostatic attraction of oppositely charges, zeta potential analysis was performed (Figure 2A). This technique provides the net electrical charge of the microparticles generated by their functional groups. In the case of nPSi, its negative zeta potential value $(-29.06 \pm 0.06 \mathrm{mV})$ would correspond to the negatively charged silanol groups produced by the chemical oxidation with $\mathrm{H}_{2} \mathrm{O}_{2}$ [46]. nPSi-Chi showed positive values (16.5 \pm 0.6 $\mathrm{mV}$ ) because the grafting with chitosan would generate a rich aminated surface [47]. On the other hand, the sharp negative zeta potential of $n P S i-\beta C D(-39.8 \pm 1.73 \mathrm{mV})$ was according to $\beta C D$ value 
$(-28.2 \pm 9 \mathrm{mV})$, which is generated by the hydrophilic outer surface cavity ( $\mathrm{C}-\mathrm{OH}$ groups) of $\beta \mathrm{CD}$ molecules [48].
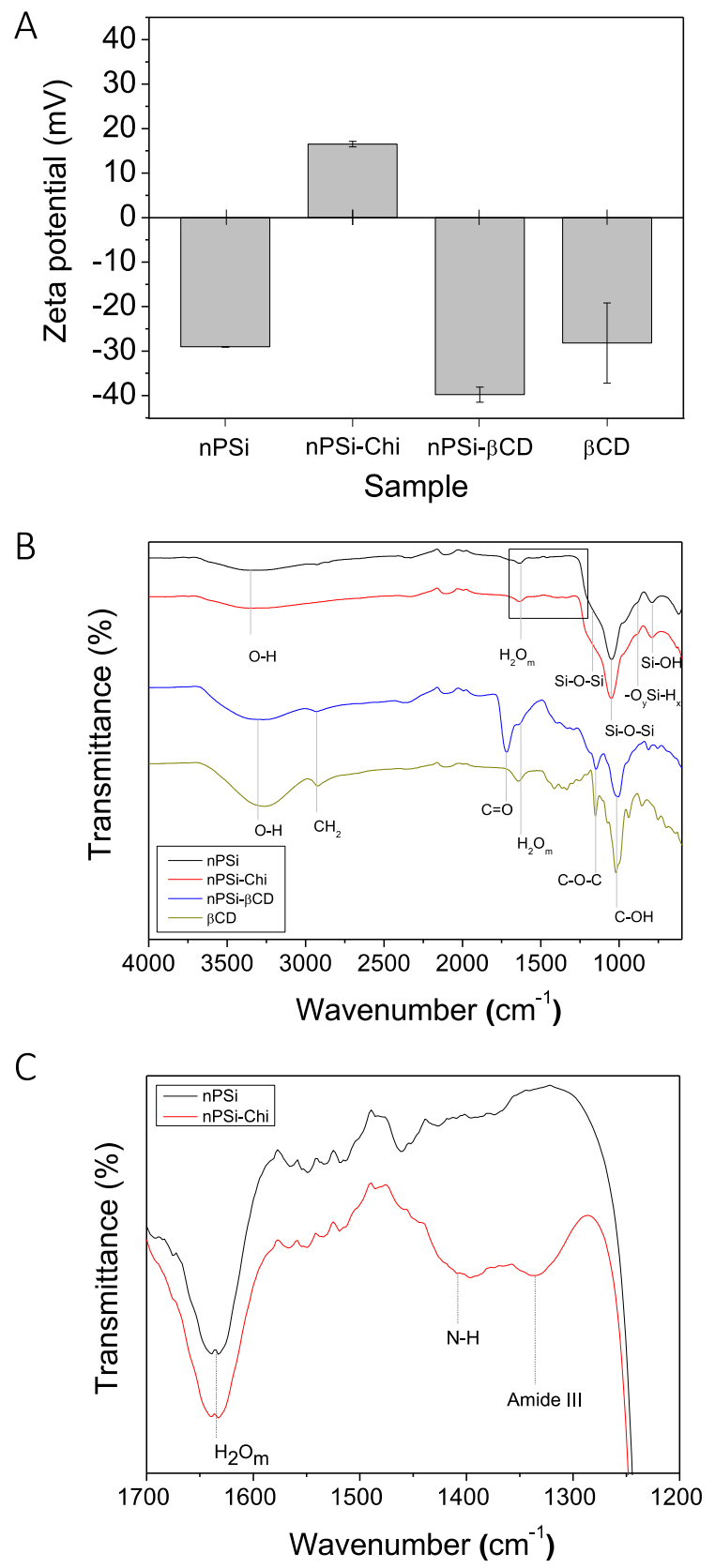

Figure 2. Monitoring of the synthesis process of $n P S i-\beta C D$ composite microparticles via: (A) Zeta potential and (B) Attenuated total reflectance Fourier transform infrared spectroscopy analysis (ATR-FTIR) (C) Zoom in of ATR-FTIR spectra.

In that sense, ATR-FTIR analysis was performed to determine the chemical changes of nPSi microparticles during the cascade synthesis processes (Figure 2B). The spectrum of nPSi showed a sharp transmittance peak at $1050 \mathrm{~cm}^{-1}$ with a shoulder at $1170 \mathrm{~cm}^{-1}$, which both correspond to $\mathrm{Si}-\mathrm{O}-\mathrm{Si}$ stretching mode [49]. Besides, weak bands at 880 and $795 \mathrm{~cm}^{-1}$ related to $-\mathrm{O}_{\mathrm{y}} \mathrm{Si}-\mathrm{H}_{\mathrm{x}}$ and $\mathrm{SiOH}$, respectively, and the $\mathrm{O}-\mathrm{H}$ stretching band from $\mathrm{SiOH}$ and adsorbed $\mathrm{H}_{2} \mathrm{O}$ at $3350 \mathrm{~cm}^{-1}$ were detected [49]. Moreover, molecular water $\left(\mathrm{H}_{2} \mathrm{O}_{\mathrm{m}}\right)$ absorbance band was observed at $1630 \mathrm{~cm}^{-1}$ [50]. These detected functional groups are in agreement with the chemical oxidation of nPSi via $\mathrm{H}_{2} \mathrm{O}_{2}$. On the other hand, the spectrum of nPSi-Chi presented the same functional groups as nPSi plus weak 
bands of N-H and amide III detected at 1408 and 1320-1346 $\mathrm{cm}^{-1}$ [51-53], respectively (Figure 2C). Those bands are related to the polyamino-saccharide chains of Chi, which were used to link the $\beta C D$ polymer with nPSi microparticles. Regarding the spectrum of nPSi- $\beta C D$, bands corresponded to the spectrum of native $\beta C D$ were observed: $\mathrm{C}-\mathrm{OH}$ stretching $\left(1021 \mathrm{~cm}^{-1}\right)$ [49], $\mathrm{C}-\mathrm{O}-\mathrm{C}$ stretching $\left(1150 \mathrm{~cm}^{-1}\right)$ [13], $\mathrm{H}_{2} \mathrm{O}_{\mathrm{m}}\left(1630 \mathrm{~cm}^{-1}\right)$ [50], $\mathrm{CH} 2$ asymmetric stretching $\left(2930 \mathrm{~cm}^{-1}\right)$ and O-H stretching from hydroxyl groups $\left(3300 \mathrm{~cm}^{-1}\right)$ [49]. nPSi- $\beta C D$ barely showed an extra band than $\beta C D$ at $1721 \mathrm{~cm}^{-1}$ which correspond to $\mathrm{C}=\mathrm{O}$ groups generated during the polymerization achieved between $\beta C D$ and citric acid [49].

SEM images were produced (Figure 3A) to analyze the size and morphology of samples at the different stages of synthesis. Moreover, the obtained distribution size from these images is shown in Figure 3B. nPSi and nPSi-Chi presented irregular shapes with an average size of 2.0-2.5 $\mu \mathrm{m}$, and both kind of microparticles showed rougher surface due to their columnar pores of $\sim 50 \mathrm{~nm}$ width. In addition, gravimetric analysis presented an average porosity of $75 \pm 5 \%$. In the case of the nPSi- $\beta C D$ sample, the microparticle shapes were also irregular with a higher size around of $14.0 \mu \mathrm{m}$, and their faces exhibited a softer appearance. In fact, folds produced by the polymerization could be also observed. The increase in particle size may have been because the small particles agglomerated during the polymerization forming higher particles. Similar size distribution of this kind of particles for oral drug delivery system has been previously reported by Salonen et al. [54]. On the other hand, EDX analysis was performed on each sample (Figure 3C1) and the atomic percentage and C/Si ratio were obtained (Figure 3C2). nPSi mainly exhibited $\mathrm{Si}$ and $\mathrm{O}$ signal due to the oxidation performed by $\mathrm{H}_{2} \mathrm{O}_{2}$. Although the C/Si ratio was $0.76 \pm 0.2, \mathrm{C}$ signal was considerable high $(\sim 18 \%)$. This was most probably due to contamination when handling. In the case of nPSi-Chi, due to the previous characterization (Zeta potential and ATR-FTIR), N signal from amines groups of the incorporated chitosan was expected to be identified but it was not. This can be explained because incorporated chitosan was most likely a superficial layer and N signal was not strong enough to be detected by EDX technique. However, it is possible to observe that the C/Si ratio increased twice up to $1.5 \pm 0.3$ due to the polymer grafting [55]. Regarding the $n P S i-\beta C D$ sample, a high increase of $C$ signal was identified: the $C / S i$ was raised up to $17.4 \pm 8$ due to the in situ polymerization of $\beta C D$ and citric acid. In fact, $\mathrm{Na}$ and $\mathrm{P}$ traces from the catalyst were also detected.

A
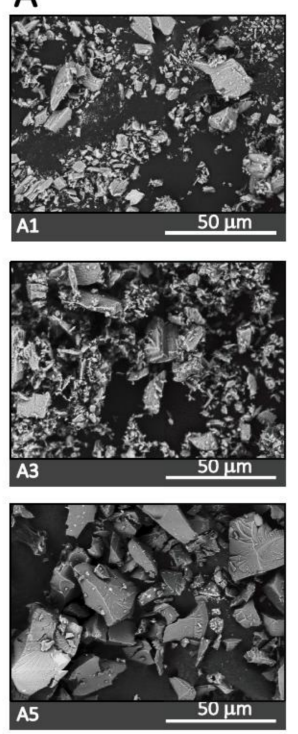

B
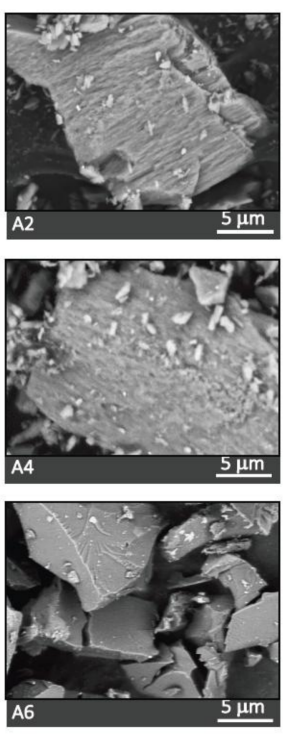
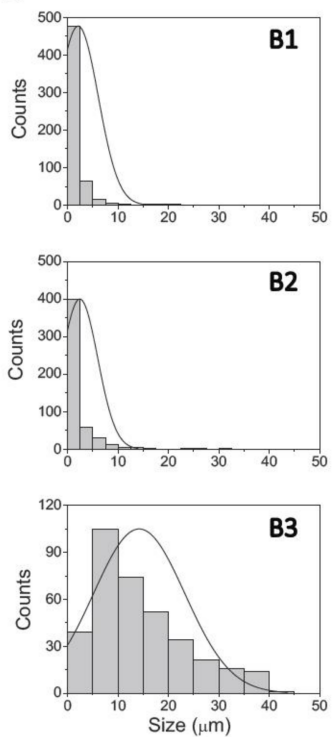

C
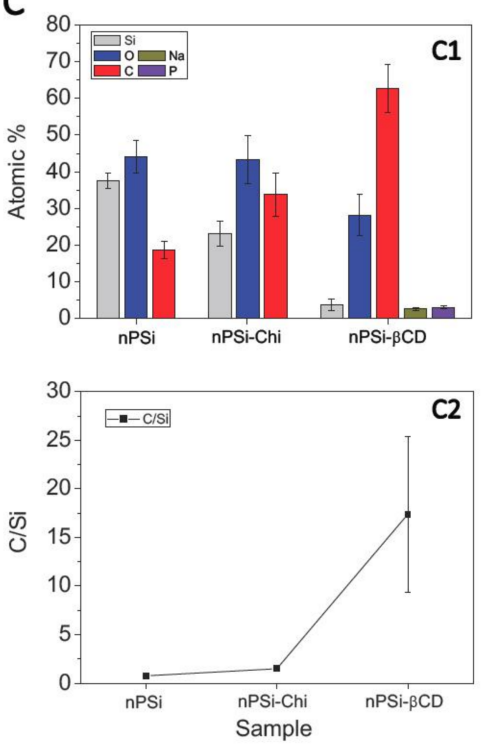

Figure 3. (A) Scanning electron microscope images (SEM) of samples at the different stages of synthesis: (A1,A2) for nPSi, (A3,A4) for nPSi-Chi, (A5,A6) for nPSi- $\beta C D$. (B) Histograms of particle size distribution: (B1) for $\mathrm{nPSi}$, (B2) for nPSi-Chi, (B3) for $\mathrm{nPSi}-\beta \mathrm{CD}$. (C) Atomic \% and C/Si ratio of samples obtained from energy-dispersive $\mathrm{X}$-ray analysis $(\mathrm{EDX}),(\mathbf{C} 1, \mathbf{C} 2)$, respectively. 
In order to evaluate changes in $\mathrm{nPSi}-\beta \mathrm{CD}$ composite microparticles with the loaded polyphenols, same set of previous physicochemical characterization was carried out. Figure 4A shows how zeta potential of $n P S i-\beta C D$ was reduced after the addition of both polyphenols: $n P S i-\beta C D / C A$ and $n P S i-\beta C D / P i n$ presented 5.5 and $10.4 \mathrm{mV}$ lower zeta potential values than $\mathrm{nPSi}-\beta C D$, respectively. Regarding the ATR-FTIR analysis (Figure $4 \mathrm{~B}$ ), nPSi- $\beta C D / C A$ and $n P S i-\beta C D / P i n$ spectra exhibited the same functional groups than $n P S i-\beta C D$ spectrum. Nevertheless, both $n P S i-\beta C D / C A$ and $n P S i-\beta C D / P i n$ exhibited two extra bands related to the bending modes of $\mathrm{CH}$, which are associated to incorporation of both polyphenols (Figure $4 \mathrm{C}$ ): $\beta(\mathrm{CH})$ and $\gamma(\mathrm{CH})$ at 1187 and $940 \mathrm{~cm}^{-1}$, respectively. $\beta$ denotes in-plane bending modes and $\gamma$ designates out-of-plane bending modes [56].

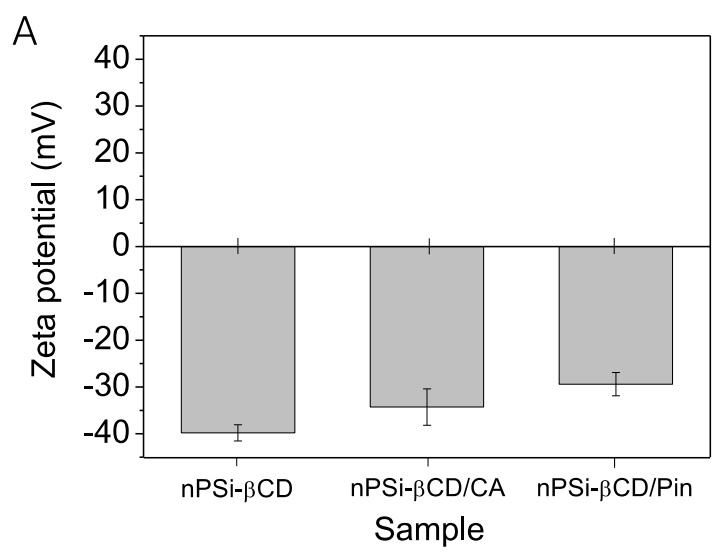

B

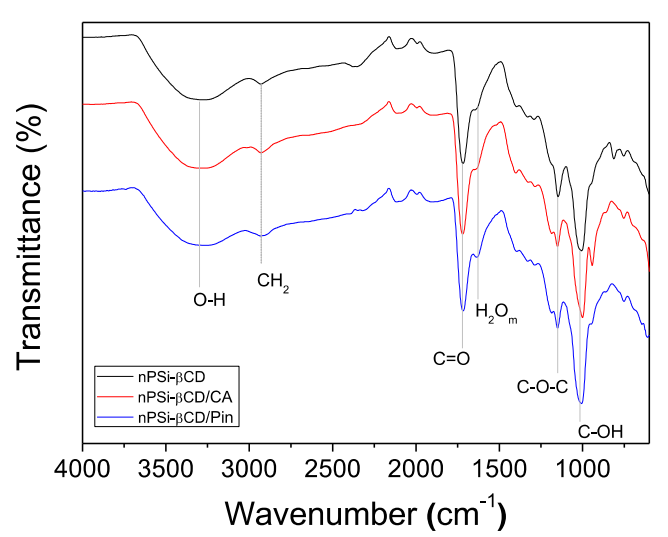

C

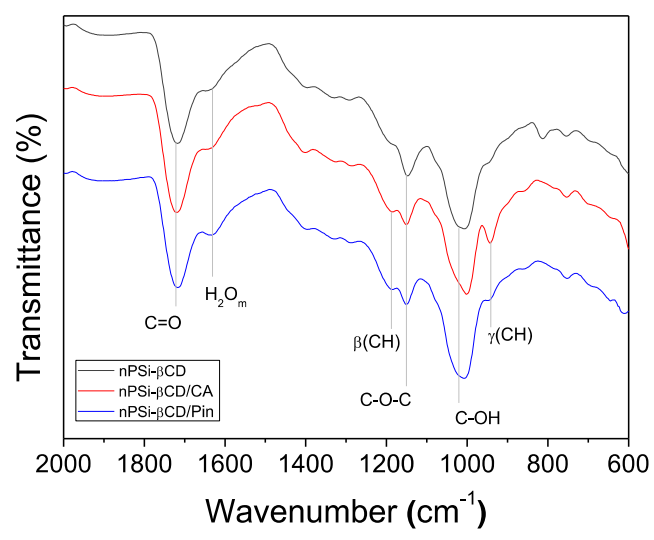

Figure 4. Monitoring of the polyphenols loading on PSi- $\beta C D$ composite microparticles via: (A) Zeta potential and (B) Attenuated total reflectance Fourier transform infrared spectroscopy analysis (ATR-FTIR). (C) Zoom in of ATR-FTIR spectra. 
Regarding morphology, which was observed by SEM images (Figure 5A), nPSi- $\beta$ CD/CA and $n P S i-\beta C D / P i n$ did not present significantly changes in comparison with nPSi- $\beta C D$; the surface of both $n P S i-\beta C D / C A$ and $n P S i-\beta C D / P i n$ microparticles exhibited a softer appearance and some folds produced by the polymerization. However, the size of the loaded microparticles was higher than nPSi- $\beta C D$ (Figure 5B): $\sim 19$ and $\sim 22 \mu \mathrm{m}$, respectively. As polyphenols are highly hydrophobics, they could tend to agglomerate smaller particles. As Pin is more hydrophobic than CA, this could generate more aggregation, and therefore, higher microparticles. On the other hand, EDX analysis were also performed on the samples (Figure 5C1), atomic percentage and C/Si ratio were obtained too (Figure $5 \mathrm{C} 2$ ). nPSi- $\beta \mathrm{CD} / \mathrm{CA}$ and $\mathrm{nPSi}-\beta \mathrm{CD} / \mathrm{Pin}$ did not present any more $\mathrm{Na}$ and $\mathrm{P}$ traces, and the $\mathrm{C} / \mathrm{Si}$ ratio considerably increased in comparison with $n P S i-\beta C D$ : $n P S i-\beta C D$ showed a $C / S i$ ratio of $17.4 \pm 8$, and $\mathrm{nPSi}-\beta C D / C A$ and $\mathrm{nPSi}-\beta C D /$ Pin presented $88.75 \pm 22.2$ and $105.7 \pm 30.5$, respectively.
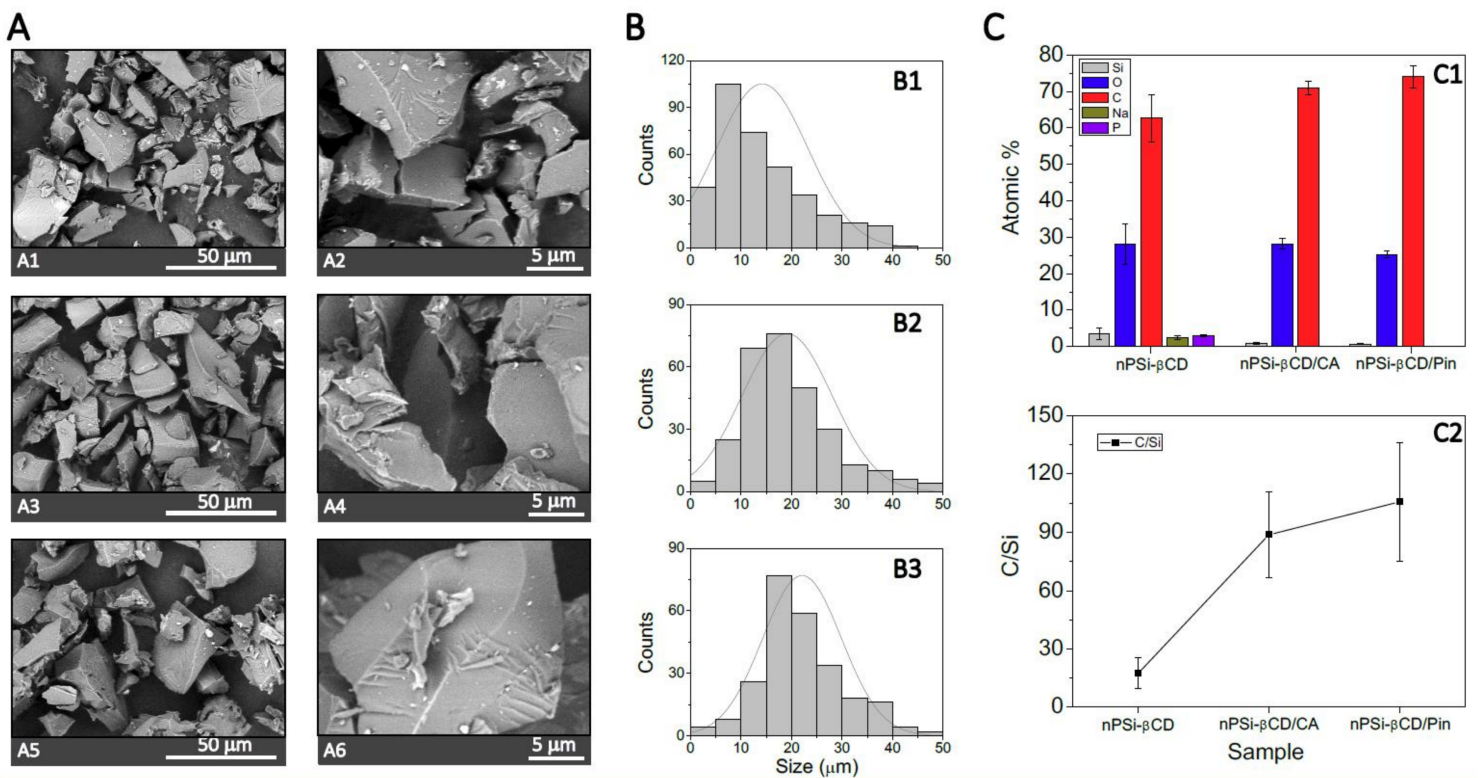

Figure 5. (A) Scanning electron microscope images (SEM) of nPSi- $\beta C D$ loading with polyphenols:

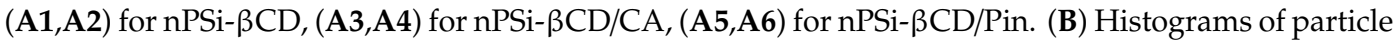
size distribution: (B1) for $n P S i-\beta C D,(B 2)$ for $n P S i-\beta C D / C A, B 3$ for $n P S i-\beta C D / P i n$. (C) Atomic \% and $\mathrm{C} / \mathrm{Si}$ ratio of samples obtained from energy-dispersive $\mathrm{X}$-ray analysis (EDX), (C1,C2), respectively.

In order to determine the functionalization degree of Chi and $\beta C D$ polymer integrated onto nPSi substrates, TGA analyses were performed (Figure 6A). The plot illustrates the percent mass as a function of samples temperature under a nitrogen purge. As expected, nPSi sample practically did not present degradation, but nPSi-Chi showed a slight decomposition of around 3\%, this is in accordance previous characterization that suggests chitosan grafting was just superficially. Moreover, the thermogravimetric analysis of native $\beta C D$ was monitored as reference. The $\beta C D$ decomposition was clearly appreciable; the first stage with was at $100{ }^{\circ} \mathrm{C}$ corresponds to the level of absorbed water $(\sim 10.5 \%)$. The second stage, which started at $310^{\circ} \mathrm{C}$ and finished at $350{ }^{\circ} \mathrm{C}$, is related to the melting, decomposition and turning into char of the glucose units of the $\beta C D$ molecules [57]. In the case of $n P S i-\beta C D$, the phenomenon was gradual, due to the stronger 3D structure net of $\beta C D$ polymer, but similar to the native $\beta C D$ reference. Considering the residual weight at $600{ }^{\circ} \mathrm{C}$, it is possible to ponder that nPSi- $\beta C D$ was composed by $32 \%$ nPSi, $62 \% \beta C D$ polymer, $3 \%$ Chi and $3 \%$ humidity. The high percent of $\beta C D$ polymer $(62 \%)$ in composite composition can be explained, in addition to the electrostatic interactions with polymers showed by zeta potential, with porosity of samples which also worked as an anchor holding the polymer film. 
A

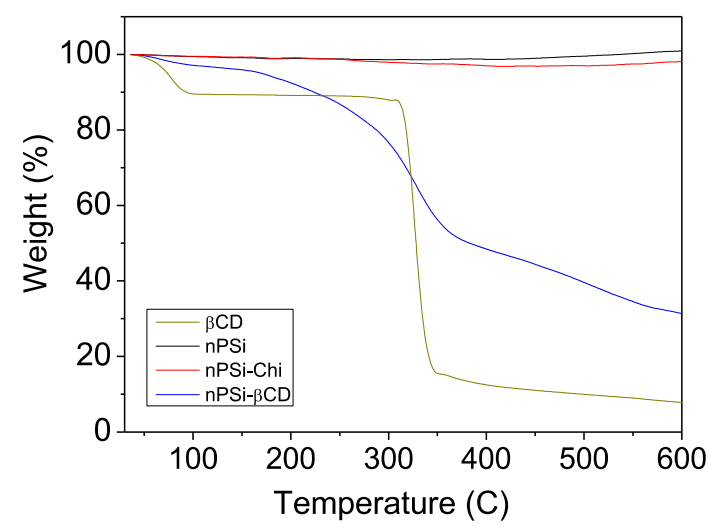

B

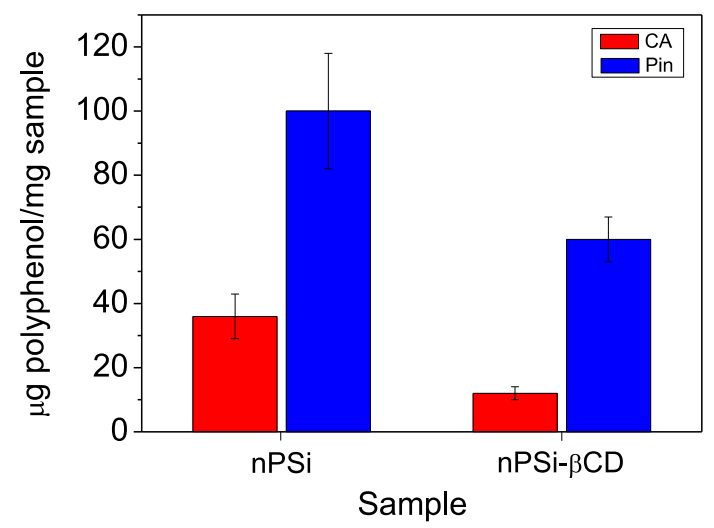

Figure 6. (A) Thermogravimetric analysis (TGA) of microparticles at different stages of synthesis, and (B) Polyphenols capacity loading of nPSi- $\beta C D$ composite microparticles.

$\%$ PEE and \%PLE of samples were determined by UV-Vis spectroscopy at 310 and $322 \mathrm{~nm}$ for $\mathrm{CA}$ and Pin, respectively. Although nPSi (control) did not exhibit a chemical surface compatible with polyphenols, samples presented high values of \%PEE $50 \pm 2.0$ and $97.5 \pm 2.0$ for CA and Pin respectively. This can be explained by the high surface area of their nanopores. In the case of nPSi- $\beta C D$, microparticles exhibited $16.6 \pm 1.0 \% \mathrm{PEE}$ and $58.5 \pm 1.5 \% \mathrm{PEE}$ for CA and Pin, respectively. In the same sense, $n P S i$ samples presented higher $\%$ PLE than $n P S i-\beta C D$. Figure $6 \mathrm{~B}$ shows the polyphenols capacity loading of both kind of microparticles. nPSi presented a load of $36 \pm 7 \mu \mathrm{g} \mathrm{CA} / \mathrm{mg}$ nPSi $(3.6 \pm 0.7 \%$ PLE) and $100 \pm 18 \mu \mathrm{g}$ Pin/mg nPSi (10.0 $\pm 1.8 \%$ PLE), and nPSi- $\beta C D$ showed a load of $12 \pm 2 \mu \mathrm{g} \mathrm{CA} / \mathrm{mg}$ $\mathrm{nPSi}(1.2 \pm 0.2 \%$ PLE) and $60 \pm 7 \mu \mathrm{g}$ Pin/mg nPSi $(6.0 \pm 0.7 \%$ PLE). Due to previous characterization results, it is very possible that polyphenols were mainly adsorbed in the large corona of $\beta C D$ polymer around the small nPSi microparticles, which were the substrate of the composite.

To evaluate the polyphenols controlled release functionality, loaded microparticles of nPSi and $n P S i-\beta C D$ were immersed in PBS batches at $37^{\circ} \mathrm{C}$ under stirring. The obtained polyphenols release profiles are shown in Figure 7A1,A2 for CA, and Figure 7B1,B2 for Pin. After $24 \mathrm{~h}$ of release, all samples presented higher values of \%cumulative release. nPSi samples showed $97.6 \pm 17.6$ and $94.2 \pm 17.0$ for $C A$ and Pin, respectively. In the case of $n P S i-\beta C D$, microparticles exhibited $93.8 \pm 11.2$ and $92.3 \pm 11.0$ for $\mathrm{CA}$ and Pin, respectively. Profiles presented a clear contrasting behavior between the control (nPSi) and composite (nPSi- $\beta C D$ ). Results visibly showed that $n P S i-\beta C D$ worked much better than nPSi: both polyphenols retained into nPSi showed a fast release profile during the first minutes, in contrast with nPSi- $\beta C D$, which showed a controlled released for more than $5 \mathrm{~h}$.

To attain deeper perception of the mechanisms that govern the release of polyphenols from the samples, three release models were fitted to the experimental data: first order, Higuchi and Korsmeyer-Peppas models (Table 1). In the case of CA release, according to the $r^{2}$ obtained values for $\mathrm{nPSi}$, it presented better adjustment with the first order model, where immediate-release dosage was dispersed in a single action [58]. However, for the release of CA using $n P S i-\beta C D, C A$ release kinetics were described with a more accurate precision by the Korsmeyer-Peppas model. This means that the governing factor of CA release was not the dissolution from samples, but a Fickian diffusion process [41]. Moreover, in that sense, since the release exponent $n$ from the Korsmeyer-Peppas model was smaller than 0.5 , only diffusive release can be suggested. Therefore, erosion process could be insignificant [41]. For the case of Pin, both release profiles from nPSi and nPSi- $\beta C D$ microparticles, were better adjusted to the Korsmeyer-Peppas model. However, nPSi presented an $n$ value closed to zero. Regarding $n P S i-\beta C D$, it showed an $n>0.5$, which suggest that besides Fickian diffusion, erosion process could also be contributing in the Pin release [41]. 
A1

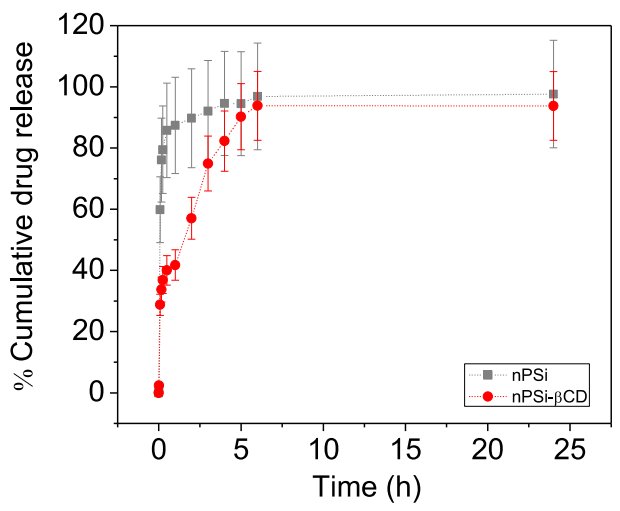

B1

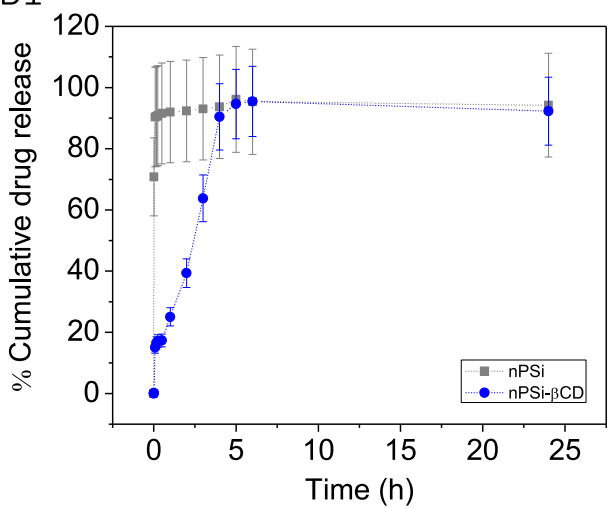

A2

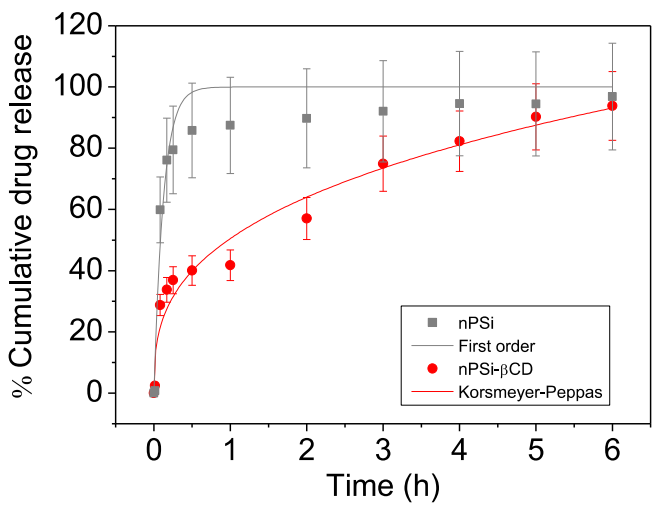

B2

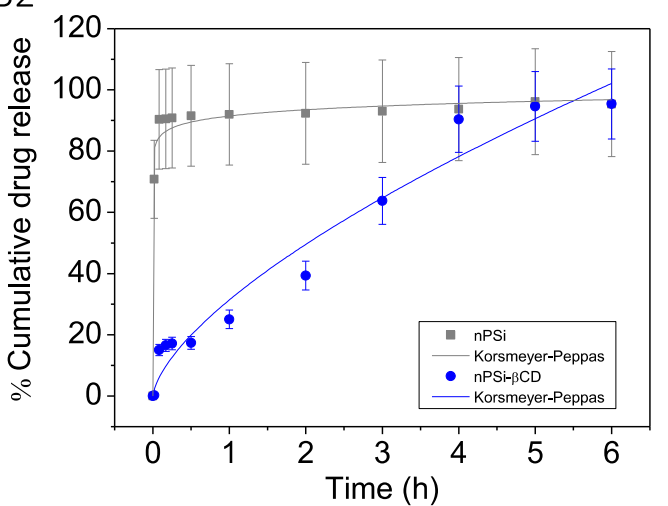

Figure 7. Polyphenols release profiles in phosphate-buffered saline (PBS) at $37^{\circ} \mathrm{C}:(\mathbf{A 1}, \mathbf{A} 2) \mathrm{CA}$ and (B1,B2) Pin.

Table 1. In vitro release kinetics of caffeic acid and pinocembrin in PBS at $37^{\circ} \mathrm{C}$.

\begin{tabular}{ccccccccc}
\hline \multirow{2}{*}{ Polyphenol } & \multirow{2}{*}{ Sample } & \multicolumn{2}{c}{ First order } & \multicolumn{2}{c}{ Higuchi } & \multicolumn{2}{c}{ Korsmeyer-Peppas } \\
\cline { 3 - 8 } & & \multicolumn{2}{c}{$\ln M_{t}-\ln M_{0}=k_{1} t$} & \multicolumn{2}{c}{$M_{t}=k_{H} t^{1 / 2}$} & \multicolumn{3}{c}{$\frac{M_{t}}{M_{\infty}}=k_{K P} t^{n}$} \\
\cline { 3 - 9 } & & $k_{1}\left(\% h^{-1}\right)$ & $r_{a d j}^{2}$ & $k_{H}\left(\% h^{-1 / 2}\right)$ & $r_{a d j}^{2}$ & $k_{K P}\left(h^{-n}\right)$ & $n$ & $r_{a d j}^{2}$ \\
\hline \multirow{2}{*}{ Caffeic acid } & nPSi & 8.1047 & 0.9355 & 52.7074 & -0.0040 & 79.7830 & 0.197 & 0.7832 \\
& nPSi- $\beta C D$ & 0.5694 & 0.7982 & 41.6744 & 0.9074 & 50.4833 & 0.3419 & 0.9649 \\
\multirow{2}{*}{ Pinocembrin } & nPSi & 76.3252 & 0.9271 & 54.5954 & -2.1444 & 91.4797 & 0.0317 & 0.9774 \\
& nPSi- $\beta C D$ & 0.3892 & 0.9433 & 38.5733 & 0.9451 & 31.3890 & 0.6584 & 0.9654 \\
\hline
\end{tabular}

To evaluate the cytotoxic effect of CA and Pin, human umbilical vein endothelial cells (HUVECs) cultures were performed. HUVECs are a classic model to study endothelial functions, such as angiogenesis. Angiogenesis is the formation of new blood vessels from pre-existing vessels [59]. Although it is a physiological process, the abnormal growth of vessels promotes the development and/or progression of some diseases such as cardiovascular diseases. Regarding this, the MTS test was used to study the impact of CA and Pin on the viability of HUVECs. Results showed that viability gradually decreased and responded in a dose-dependent manner for both polyphenols. In the case of CA, cell viability was slightly reduced from $100 \%$ to $80 \%$ for concentrations from 2 to $200 \mu \mathrm{M}(p>0.05)$, while surviving cells were $\leq 70 \%$ for concentrations $\geq 500 \mu \mathrm{M}$. $(p<0.01)$ (Figure $8 \mathrm{~A})$. Regarding to the effect of Pin (Figure $8 \mathrm{~B}$ ), the viability was higher than $80 \%$ from 2 to $100 \mu \mathrm{M}$, but it decreased to $50 \%$ at $200 \mu \mathrm{M}(p>0.05)$. Moreover, cell viability was reduced to less than $20 \%$ at concentrations $\geq 500$ $\mu \mathrm{M}(p<0.01)$. According to this, concentrations up to 200 and $100 \mu \mathrm{M}$ for CA and Pin, respectively, maintained cell viability $\geq 80 \%$, that is to say, they did not generate cellular cytotoxicity. 
A

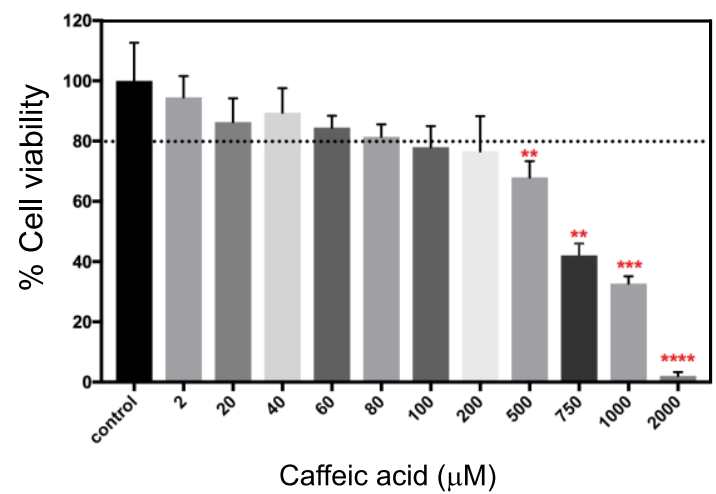

B

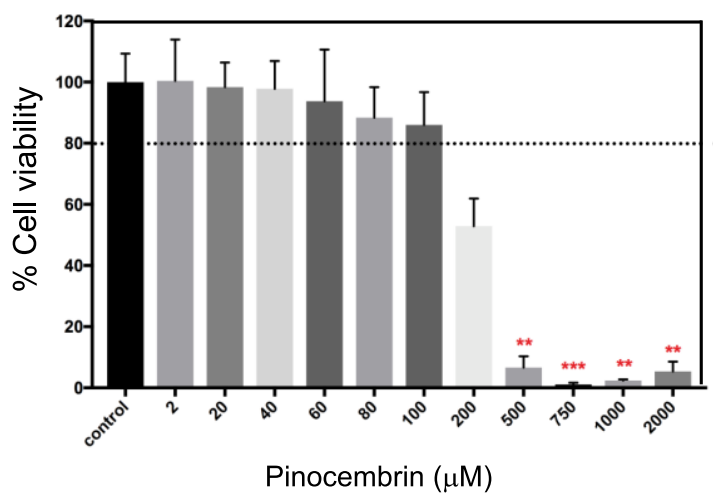

Figure 8. Viability of HUVECs treated with polyphenols. Cells were exposed to different concentrations of polyphenols for $24 \mathrm{~h}$ and cellular viability was measured by tetrazolium salt (MTS) assay. (A) Cells treated with 2-2000 mM of caffeic acid, and (B) Cells treated with 2-2000 mM of pinocembrin. Unexposed cells to $n P S i-\beta C D$ microparticles were used as a control. The dashed line indicates the cell viability of $80 \%$. All results are presented as the mean \pm standard deviation (SD). The experimental data from all relevant studies were analyzed using Analysis of Variance (ANOVA) and Kruskal-Wallis test, which indicate the statistical significance when the percentage of cells viability exposed to the different microparticle concentrations are different from the control. ${ }^{* *} p<0.01,{ }^{* * *} p<0.001,{ }^{* * * *} p<0.0001,(\mathrm{n}=3)$.

On the other hand, the effect nPSi- $\beta C D$ microparticles on the viability of HUVECs was also studied. Cells were cultured in the presence of composite microparticles at concentrations of $0.25,0.50$, 1.25 and $2.5 \mathrm{mg} / \mathrm{mL}$ for 6 and $24 \mathrm{~h}$. In the microscopic observation (Figure 9), HUVECs exposed to the lowest concentrations $(0.25$ and $0.50 \mathrm{mg} / \mathrm{mL})$ exhibited a normal flattened and thin morphology, suggesting that microparticles were well tolerated by cells. Instead, the highest concentrations (1.25 and $2.5 \mathrm{mg} / \mathrm{mL}$ ), generated a large amount of rounded and suspended cells in the culture medium. This indicates that $\mathrm{nPSi}-\beta C D$ microparticles concentrations higher than $0.50 \mathrm{mg} / \mathrm{mL}$ were not well tolerated by HUVECs, affecting its cell adhesion capacity, an essential survival characteristic of this type of cells.
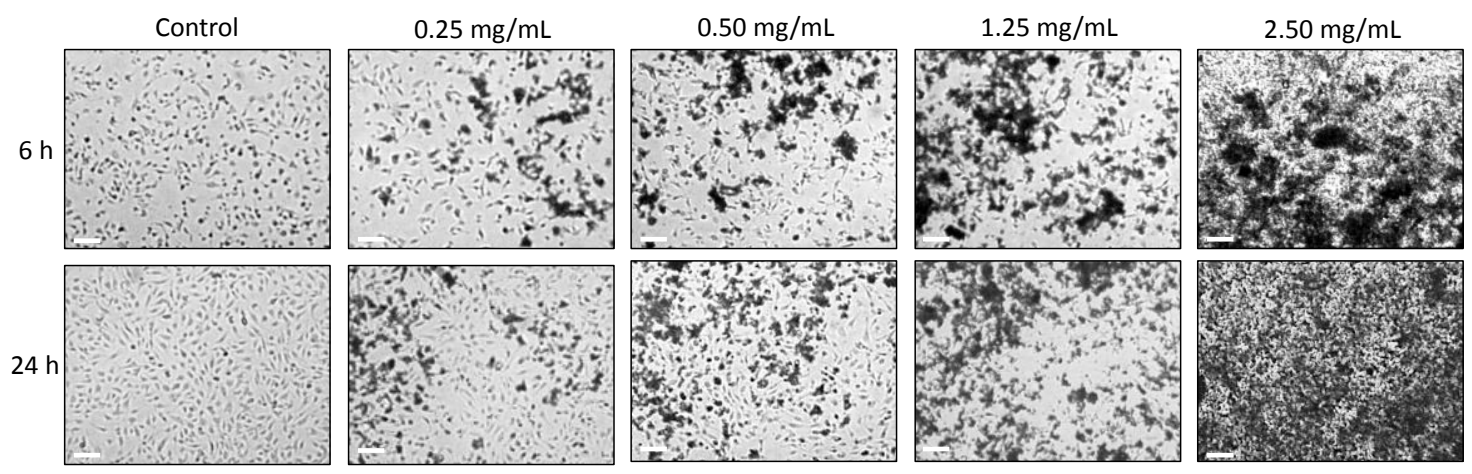

Figure 9. Microscopical images of the effect of nPSi- $\beta C D$ microparticles exposition to HUVECs during a 6 and $24 \mathrm{~h}$ culture. Images were taken at $8 \mathrm{X}$ magnification. Scale bars: $1 \mathrm{~mm}$.

Concerning the viability percentage of HUVEC exposed to different concentrations of nPSi- $\beta C D$ microparticles (Figure 10B), results showed that cell viability at $0.25 \mathrm{mg} / \mathrm{mL}$ was higher than $80 \%$ but it started to decrease at concentrations equal or higher than $0.50 \mathrm{mg} / \mathrm{mL}(63 \% ; p<0.01)$. Specifically, at concentrations of 1.25 and $2.50 \mathrm{mg} / \mathrm{mL}$, cell viability was very low reaching values as low as $20 \%$. This increase in cell mortality from $0.25 \mathrm{mg} / \mathrm{mL}$ to $\geq 1.25 \mathrm{mg} / \mathrm{mL}$ of $\mathrm{nPSi}-\beta C D$ microparticles may be due to an alteration in the basic cellular functions such as the adherence capacity affected, for example, cell communication, differentiation and migration leading to cell death [60]. 
A

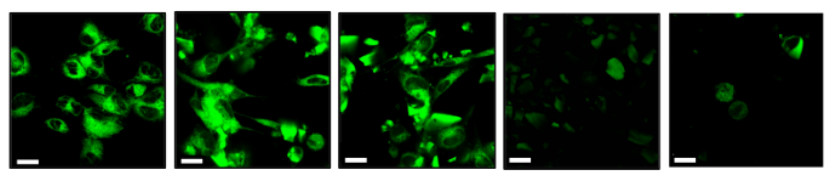

B

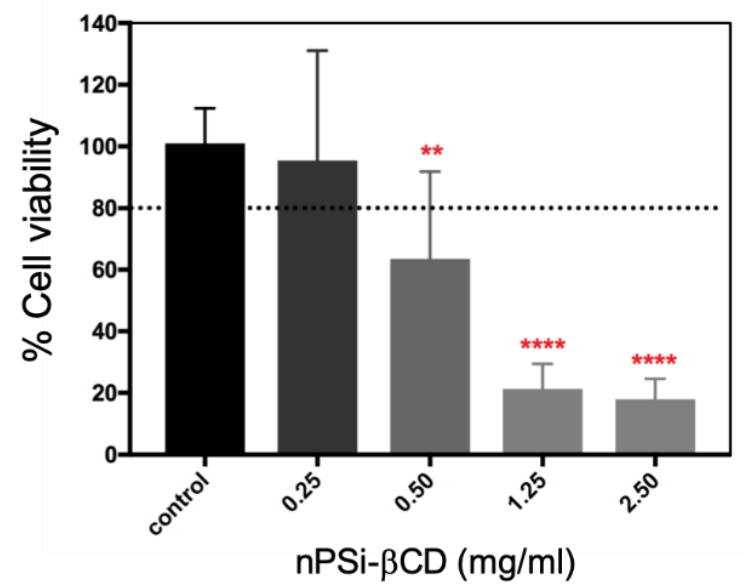

Figure 10. Cytotoxicity of HUVECs exposed to nPSi- $\beta C D$ microparticles. The cells were exposed for $6 \mathrm{~h}$ and then cellular viability was evaluated with CellTiter-FluorTM assay and fluorescence intensity measuring was with confocal laser microscope (A) HUVEC s exposed to $n P S i-\beta C D$ microparticles. Scale bars: $20 \mu \mathrm{m}$. (B) Viability percentage of cells exposed to composite microparticles. Unexposed cells to nPSi- $\beta C D$ microparticles were used as a control. Dashed line indicates cell viability of $80 \%$. All results are presented as the mean \pm standard deviation (SD). The experimental data from all the studies were analyzed using Analysis of Variance (ANOVA) and Kruskal-Wallis test, which indicate the statistical significance when the percentage of cells viability exposed to the different microparticles concentrations are different from the control. ${ }^{* *} p<0.01,{ }^{* * * *} p<0.0001$. $(\mathrm{n}=3)$.

\section{Conclusions}

Physicochemical characterizations showed that nPSi- $\beta C D$ microparticles were suitable to be used an alternative as carrier and controlled oral delivery system of both polyphenols, CA and Pin. The release profiles indicated that $n P S i-\beta C D$ composite presented a better-controlled release of polyphenols than $n P S i$ without $\beta C D$ polymer. Moreover, $\mathrm{nPSi}-\beta C D$ samples loaded higher amount of Pin than CA, and the release of Pin was higher controlled than CA. For the CA case, a purely diffusive mechanism of release was suggested, but for the Pin, erosion process could be also contributing during the release. On the other hand, $\mathrm{nPSi}-\beta \mathrm{CD}$ microparticles presented cytocompatibility HUVECs culture at concentrations of $0.25 \mathrm{mg} / \mathrm{mL}$. Then, these results indicate that $\mathrm{nPSi}-\beta C D$ composite microparticles could be safely used as an alternative oral delivery system to improve controlled release and bioavailability of CA and Pin, and eventually other polyphenols with therapeutic potential.

Author Contributions: D.G.-O., L.A.S. and J.H.-M. conceived and designed experiments; T.P. and G.R.-S. synthetized the nPSi and nPSi- $\beta C D$ microparticles; D.G.-O., T.P., G.R.-S. and J.H.-M. performed the physicochemical characterization; D.G.-O. and D.S.P.A. performed the biological experiments, D.G.-O. and J.H.-M. analyzed the data; D.G.-O., G.R.-S., L.A.S. and J.H.-M. contributed the reagent and analytical tools; G.D.-O. and J.H.-M. wrote the manuscript. All authors revised the manuscript.

Funding: This work was financially supported by Fondo Nacional de Desarrollo Científico Tecnológico FONDECYT-Chile (Grant numbers 11180395 and 1171765), CONICYT Scholarship (21140154) and UCT project (2017PF-JH-07).

Conflicts of Interest: The authors declare no conflict of interest. 


\section{References}

1. Li, A.N.; Li, S.; Zhang, Y.J.; Xu, X.R.; Chen, Y.M.; Li, H.B. Resources and biological activities of natural polyphenols. Nutrients 2014, 6, 6020-6047. [CrossRef] [PubMed]

2. Fraga, C.G.; Galleano, M.; Verstraeten, S.V.; Oteiza, P.I. Basic biochemical mechanisms behind the health benefits of polyphenols. Mol. Asp. Med. 2010, 31, 435-445. [CrossRef] [PubMed]

3. Silva-Carvalho, R.; Baltazar, F.; Almeida-Aguiar, C. Propolis: A Complex Natural Product with a Plethora of Biological Activities That Can Be Explored for Drug Development. Evid. Based Complement. Altern. Med. 2015, 2015, 206439. [CrossRef] [PubMed]

4. Grange, J.M.; Davey, R.W. Antibacterial properties of propolis (bee glue). J. R. Soc. Med. 1990, 83, $159-160$. [CrossRef] [PubMed]

5. Dobrowolski, J.W.; Vohora, S.B.; Sharma, K.; Shah, S.A.; Naqvi, S.A.H.; Dandiya, P.C. Antibacterial, antifungal, antiamoebic, antiinflammatory and antipyretic studies on propolis bee products. J. Ethnopharmacol. 1991, 35, 77-82. [CrossRef]

6. Daleprane, J.B.; Abdalla, D.S. Emerging roles of propolis: Antioxidant, cardioprotective, and antiangiogenic actions. Evid. Based Complement. Altern. Med. 2013, 2013, 175135. [CrossRef] [PubMed]

7. Tan-No, K.; Nakajima, T.; Shoji, T.; Nakagawasai, O.; Niijima, F.; Ishikawa, M.; Endo, Y.; Sato, T.; Satoh, S.; Tadano, T. Anti-inflammatory effect of propolis through inhibition of nitric oxide production on carrageenin-induced mouse paw edema. Biol. Pharm. Bull. 2006, 29, 96-99. [CrossRef] [PubMed]

8. Grunberger, D.; Banerjee, R.; Eisinger, K.; Oltz, E.M.; Efros, L.; Caldwell, M.; Estevez, V.; Nakanishi, K. Preferential cytotoxicity on tumor cells by caffeic acid phenethyl ester isolated from propolis. Experientia 1988, 44, 230-232. [CrossRef] [PubMed]

9. Daleprane, J.B.; Freitas, V.S.; Pacheco, A.; Rudnicki, M.; Faine, L.A.; Dörr, F.A.; Ikegaki, M.; Salazar, L.A.; Ong, T.P.; Abdalla, D.S. Anti-atherogenic and anti-angiogenic activities of polyphenols from propolis. J. Nutr. Biochem. 2012, 23, 557-566. [CrossRef] [PubMed]

10. Woodman, O.L.; Chan, E.C. Vascular and anti-oxidant actions of flavonols and flavones. Clin. Exp. Pharmacol. Physiol. 2004, 31, 786-790. [CrossRef]

11. Sedlak, L.; Wojnar, W.; Zych, M.; Wyględowska-Promieńska, D.; Mrukwa-Kominek, E.; Kaczmarczyk-Sedlak, I. Effect of Resveratrol, a Dietary-Derived Polyphenol, on the Oxidative Stress and Polyol Pathway in the Lens of Rats with Streptozotocin-Induced Diabetes. Nutrients 2018, 10, 1423. [CrossRef] [PubMed]

12. Bijak, M.; Ziewiecki, R.; Saluk, J.; Ponczek, M.; Pawlaczyk, I.; Krotkiewski, H.; Wachowicz, B.; Nowak, P. Thrombin inhibitory activity of some polyphenolic compounds. Med. Chem. Res. 2014, 23, 2324-2337. [CrossRef] [PubMed]

13. Paeng, S.H.; Jung, W.K.; Park, W.S.; Lee, D.S.; Kim, G.Y.; Choi, Y.H.; Seo, S.K.; Jang, W.H.; Choi, J.S.; Lee, Y.M.; et al. Caffeic acid phenethyl ester reduces the secretion of vascular endothelial growth factor through the inhibition of the ROS, PI3K and HIF- $1 \alpha$ signaling pathways in human retinal pigment epithelial cells under hypoxic conditions. Int. J. Mol. Med. 2015, 35, 1419-1426. [CrossRef] [PubMed]

14. Gao, Y.; Liu, F.; Fang, L.; Cai, R.; Zong, C.; Qi, Y. Genkwanin inhibits proinflammatory mediators mainly through the regulation of miR-101/MKP-1/MAPK pathway in LPS-activated macrophages. PLoS ONE 2014, 9, e96741. [CrossRef] [PubMed]

15. Turrini, E.; Ferruzzi, L.; Fimognari, C. Potential Effects of Pomegranate Polyphenols in Cancer Prevention and Therapy. Oxid. Med. Cell. Longev. 2015, 2015, 938475. [CrossRef] [PubMed]

16. Vermerris, W.; Nicholson, R. Phenolic Compound Biochemistry; Springer: Dordrecht, The Nertherlands, 2006; ISBN 9781402051630.

17. Manach, C.; Scalbert, A.; Morand, C.; Rémésy, C.; Jiménez, L. Polyphenols: Food sources and bioavailability. Am. J. Clin. Nutr. 2004, 79, 727-747. [CrossRef]

18. Barrientos, L.; Herrera, C.L.; Montenegro, G.; Ortega, X.; Veloz, J.; Alvear, M.; Cuevas, A.; Saavedra, N.; Salazar, L.A. Chemical and botanical characterization of Chilean propolis and biological activity on cariogenic bacteria Streptococcus mutans and Streptococcus sobrinus. Braz. J. Microbiol. 2013, 44, 577-585. [CrossRef]

19. Bankova, V. Chemical diversity of propolis and the problem of standardization. J. Ethnopharmacol. 2005, 100, 114-117. [CrossRef] 
20. Szliszka, E.; Sokół-Łętowska, A.; Kucharska, A.Z.; Jaworska, D.; Czuba, Z.P.; Król, W. Ethanolic Extract of Polish Propolis: Chemical Composition and TRAIL-R2 Death Receptor Targeting Apoptotic Activity against Prostate Cancer Cells. Evid. Based Complement. Altern. Med. 2013, 2013, 757628. [CrossRef]

21. Cuevas, A.; Saavedra, N.; Rudnicki, M.; Abdalla, D.S.; Salazar, L.A. ERK1/2 and HIF1 $\alpha$ Are Involved in Antiangiogenic Effect of Polyphenols-Enriched Fraction from Chilean Propolis. Evid. Based Complement. Altern. Med. 2015, 2015, 187575. [CrossRef] [PubMed]

22. Cuevas, A.; Saavedra, N.; Cavalcante, M.F.; Salazar, L.A.; Abdalla, D.S. Identification of microRNAs involved in the modulation of pro-angiogenic factors in atherosclerosis by a polyphenol-rich extract from propolis. Arch. Biochem. Biophys. 2014, 557, 28-35. [CrossRef] [PubMed]

23. Pandey, K.B.; Rizvi, S.I. Plant polyphenols as dietary antioxidants in human health and disease. Oxid. Med. Cell. Longev. 2009, 2, 270-278. [CrossRef] [PubMed]

24. Gu, H.F.; Mao, X.Y.; Du, M. Prevention of breast cancer by dietary polyphenols-role of cancer stem cells. Crit. Rev. Food Sci. Nutr. 2019, 1-16. [CrossRef] [PubMed]

25. Potì, F.; Santi, D.; Spaggiari, G.; Zimetti, F.; Zanotti, I. Polyphenol Health Effects on Cardiovascular and Neurodegenerative Disorders: A Review and Meta-Analysis. Int. J. Mol. Sci. 2019, 20, 351. [CrossRef] [PubMed]

26. Gorinstein, S.; Leontowicz, H.; Leontowicz, M.; Jesion, I.; Namiesnik, J.; Drzewiecki, J.; Park, Y.S.; Ham, K.S.; Giordani, E.; Trakhtenberg, S. Influence of two cultivars of persimmon on atherosclerosis indices in rats fed cholesterol-containing diets: Investigation in vitro and in vivo. Nutrition 2011, 27, 838-846. [CrossRef]

27. Norata, G.D.; Marchesi, P.; Passamonti, S.; Pirillo, A.; Violi, F.; Catapano, A.L. Anti-inflammatory and anti-atherogenic effects of cathechin, caffeic acid and trans-resveratrol in apolipoprotein E deficient mice. Atherosclerosis 2007, 191, 265-271. [CrossRef]

28. D'Archivio, M.; Filesi, C.; Varì, R.; Scazzocchio, B.; Masella, R. Bioavailability of the polyphenols: Status and controversies. Int. J. Mol. Sci. 2010, 11, 1321-1342. [CrossRef]

29. Krook, M.A.; Hagerman, A.E. Stability of Polyphenols Epigallocatechin Gallate and Pentagalloyl Glucose in a Simulated Digestive System. Food Res. Int. 2012, 49, 112-116. [CrossRef]

30. Lesser, S.; Cermak, R.; Wolffram, S. Bioavailability of quercetin in pigs is influenced by the dietary fat content. J. Nutr. 2004, 134, 1508-1511. [CrossRef]

31. Milbury, P.E.; Vita, J.A.; Blumberg, J.B. Anthocyanins are bioavailable in humans following an acute dose of cranberry juice. J. Nutr. 2010, 140, 1099-1104. [CrossRef] [PubMed]

32. Manach, C.; Morand, C.; Gil-Izquierdo, A.; Bouteloup-Demange, C.; Rémésy, C. Bioavailability in humans of the flavanones hesperidin and narirutin after the ingestion of two doses of orange juice. Eur. J. Clin. Nutr. 2003, 57, 235-242. [CrossRef] [PubMed]

33. Simonetti, P.; Gardana, C.; Pietta, P. Caffeic acid as biomarker of red wine intake. Methods Enzymol. 2001, 335, 122-130. [PubMed]

34. Pandareesh, M.D.; Mythri, R.B.; Srinivas Bharath, M.M. Bioavailability of dietary polyphenols: Factors contributing to their clinical application in CNS diseases. Neurochem. Int. 2015, 89, 198-208. [CrossRef] [PubMed]

35. Canham, L.T. Bioactive silicon structure fabrication through nanoetching techniques. Adv. Mater. 1995, 7, $1033-1037$. [CrossRef]

36. Martín-Palma, R.J.; Hernández-Montelongo, J.; Torres-Costa, V.; Manso-Silván, M.; Muñoz-Noval, Á. Nanostructured porous silicon-mediated drug delivery. Expert Opin. Drug Deliv. 2014, 11, 1273-1283. [CrossRef] [PubMed]

37. Hernández-Montelongo, J.; Torres-Costa, V.; Martín-Palma, R.J.; Muñoz-Noval, Á.; Manso-Silván, M. Silicon-Based Nanoparticles for Biosensing and Biomedical Applications. In Encyclopedia of Inorganic and Bioinorganic Chemistry; John Wiley \& Sons, Ltd.: Hoboken, NJ, USA, 2015.

38. Maniya, N.H.; Patel, S.R.; Murthy, Z.V.P. Drug delivery with porous silicon films, microparticles, and nanoparticles. Rev. Adv. Mater. Sci. 2016, 44, 257-272.

39. Liu, D.; Zhang, H.; Herranz-Blanco, B.; Mäkilä, E.; Lehto, V.P.; Salonen, J.; Hirvonen, J.; Santos, H.A. Microfluidic assembly of monodisperse multistage $\mathrm{pH}$-responsive polymer/porous silicon composites for precisely controlled multi-drug delivery. Small 2014, 10, 2029-2038. [CrossRef]

40. Gidwani, B.; Vyas, A. A Comprehensive Review on Cyclodextrin-Based Carriers for Delivery of Chemotherapeutic Cytotoxic Anticancer Drugs. Biomed. Res. Int. 2015, 2015, 198268. [CrossRef] 
41. Hernández-Montelongo, J.; Oria, L.; Cárdenas, A.B.; Benito, N.; Romero-Sáez, M.; Recio-Sánchez, G. Nanoporous Silicon Composite as Potential System for Sustained Delivery of Florfenicol Drug. Phys. Status Solidi Basic Res. 2018, 255. [CrossRef]

42. Papadimitriou, S.; Bikiaris, D. Novel self-assembled core-shell nanoparticles based on crystalline amorphous moieties of aliphatic copolyesters for efficient controlled drug release. J. Control. Release 2009, 138, 177-184. [CrossRef] [PubMed]

43. Gibaldi,M.; Feldman, S. Establishment of sink conditions in dissolution rate determinations. Theoretical considerations and application to nondisintegrating dosage forms. J. Pharm. Sci. 1967, 56, 1238-1242. [CrossRef] [PubMed]

44. Higuchi, T. Mechanism of sustained-action medication. Theoretical analysis of rate of release of solid drugs dispersed in solid matrices. J. Pharm. Sci. 1963, 52, 1145-1149. [CrossRef] [PubMed]

45. Korsmeyer, R.W.; Gurny, R.; Doelker, E.; Buri, P.; Peppas, N.A. Mechanisms of solute release from porous hydrophilic polymers. Int. J. Pharm. 1983, 15, 25-35. [CrossRef]

46. Wu, S.H.; Lin, H.P. Synthesis of mesoporous silica nanoparticles. Chem. Soc. Rev. 2013, 42, 3862-3875. [CrossRef] [PubMed]

47. Meraz, K.A.S.; Vargas, S.M.P.; Maldonado, J.T.L.; Bravo, J.M.C.; Guzman, M.T.O.; Maldonado, E.A.L. Eco-friendly innovation for nejayote coagulation-flocculation process using chitosan: Evaluation through zeta potential measurements. Chem. Eng. J. 2016, 284, 536-542. [CrossRef]

48. Lian, T.; Peng, M.; Vermorken, A.J.M.; Jin, Y.; Luo, Z.; Van de Ven, W.J.M.; Wan, Y.; Hou, P.; Cui, Y. Synthesis and Characterization of Curcumin-Functionalized HP-beta-CD-Modified GoldMag Nanoparticles as Drug Delivery Agents. J. Nanosci. Nanotechnol. 2016, 16, 6258-6264. [CrossRef] [PubMed]

49. Hernandez-Montelongo, J.; Naveas, N.; Degoutin, S.; Tabary, N.; Chai, F.; Spampinato, V.; Ceccone, G.; Rossi, F.; Torres-Costa, V.; Manso-Silvan, M.; et al. Porous silicon-cyclodextrin based polymer composites for drug delivery applications. Carbohydr. Polym. 2014, 110, 238-252. [CrossRef] [PubMed]

50. McIntosh, I.M.; Nichols, A.R.L.; Tani, K.; Llewellin, E.W. Accounting for the species-dependence of the $3500 \mathrm{~cm}-1 \mathrm{H} 2 \mathrm{Otinfrared}$ molar absorptivity coefficient: Implications for hydrated volcanic glasses. Am. Mineral. 2017, 102, 1677-1689. [CrossRef]

51. Singh, P.; Chauhan, K.; Priya, V.; Singhal, R.K. A greener approach for impressive removal of As(III)/As(v) from an ultra-low concentration using a highly efficient chitosan thiomer as a new adsorbent. RSC Adv. 2016, 6, 64946-64961. [CrossRef]

52. Alhosseini, S.N.; Moztarzadeh, F.; Mozafari, M.; Asgari, S.; Dodel, M.; Samadikuchaksaraei, A.; Kargozar, S.; Jalali, N. Synthesis and characterization of electrospun polyvinyl alcohol nanofibrous scaffolds modified by blending with chitosan for neural tissue engineering. Int. J. Nanomed. 2012, 7, 25-34.

53. Jafary, F.; Panjehpour, M.; Varshosaz, J.; Yaghmaei, P. Stability improvement of immobilized alkaline phosphatase using chitosan nanoparticles. Braz. J. Chem. Eng. 2016, 33. [CrossRef]

54. Salonen, J.; Laitinen, L.; Kaukonen, A.M.; Tuura, J.; Björkqvist, M.; Heikkilä, T.; Vähä-Heikkilä, K.; Hirvonen, J.; Lehto, V.P. Mesoporous silicon microparticles for oral drug delivery: Loading and release of five model drugs. J. Control. Release 2005, 108, 362-374. [CrossRef] [PubMed]

55. Perruchot, C.; Khan, M.A.; Kamitsi, A.; Armes, S.P.; Von Werne, T.; Patten, T.E. Synthesis of well-defined, polymer-grafted silica particles by aqueous ATRP. Langmuir 2001, 17, 4479-4481. [CrossRef]

56. Świsłocka, R. Spectroscopic (FT-IR, FT-Raman, UV absorption, 1H and 13C NMR) and theoretical (in B3LYP/6-311++G** level) studies on alkali metal salts of caffeic acid. Spectrochim. Acta A Mol. Biomol. Spectros 2013, 100, 21-30.

57. Skiba, M.; Lahiani-Skiba, M. Novel method for preparation of cyclodextrin polymers: Physico-chemical characterization and cytotoxicity. J. Incl. Phenom. Macrocycl. Chem 2013, 74, 341-349. [CrossRef]

58. Perrie, Y.; Rades, T. FASTtrack Pharmaceutics: Drug Delivery and Targeting; Pharmaceutical Press: Philadelphia, PA, USA, 2010; ISBN 9780857110596.

59. Carmeliet, P.; Jain, R.K. Angiogenesis in cancer and other diseases. Nature 2000, 407, 249-257. [CrossRef] [PubMed]

60. Chovatiya, R.; Medzhitov, R. Stress, inflammation, and defense of homeostasis. Mol. Cell 2014, 54, 281-288. [CrossRef] [PubMed]

(C) 2019 by the authors. Licensee MDPI, Basel, Switzerland. This article is an open access article distributed under the terms and conditions of the Creative Commons Attribution (CC BY) license (http://creativecommons.org/licenses/by/4.0/). 